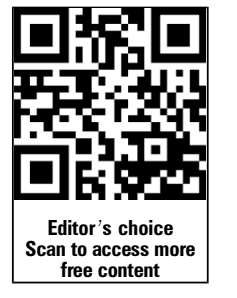

free content

\section{Handling editor Tore K Kvien \\ ${ }^{1}$ Division of Immunology and Rheumatology, Stanford University Medical Center, Palo Alto, California, USA ${ }^{2}$ Inland Rheumatology and Osteoporosis Medical Group, Upland, California, USA ${ }^{3}$ Eli Lilly and Company, Indianapolis, Indiana, USA tDeceased.}

\section{Correspondence to} Dr Mark Genovese, Stanford University Medical Center, Division of Immunology and Rheumatology, 1000 Welch Road \#203, Palo Alto 94304, CA, USA;

Genovese@Stanford.edu

Accepted 17 March 2013 Published Online First 18 April 2013

\section{SLinked}

\footnotetext{
- http://dx.doi.org/10.1136/ annrheumdis-2012-202275

- http://dx.doi.org/10.1136/ annrheumdis-2012-202450

- http://dx.doi.org/10.1136/ annrheumdis-2012-202775

- http://dx.doi.org/10.1136/

annrheumdis-2013-203261
}

\title{
A phase 2 dose-ranging study of subcutaneous tabalumab for the treatment of patients with active rheumatoid arthritis and an inadequate response to methotrexate
}

\author{
Mark C Genovese, ${ }^{1}$ Eric Lee, ${ }^{2}$ Julie Satterwhite, ${ }^{3, \dagger}$ Melissa Veenhuizen, ${ }^{3}$ \\ Damon Disch, ${ }^{3}$ Pierre-Yves Berclaz, ${ }^{3}$ Stephen Myers, ${ }^{3}$ Gregory Sides, ${ }^{3,+}$ \\ Olivier Benichou ${ }^{3}$
}

\section{ABSTRACT}

Objectives To assess the dose-response relationship efficacy and safety of tabalumab, a human monoclonal antibody that neutralises membrane-bound and soluble B-cell activating factor (BAFF), in patients with rheumatoid arthritis (RA) with inadequate response to methotrexate (MTX).

Methods In this phase 2, 24-week, double-blind, placebo-controlled, dose-ranging study, patients with RA $(\mathrm{N}=158)$ on stable MTX were randomised by Bayesianadaptive method to receive $1,3,10,30,60$, or $120 \mathrm{mg}$ tabalumab or placebo subcutaneously every 4 weeks for 24 weeks. The primary objective was to test for a significant dose-response relationship using a statistical model of the proportion of patients having $\geq 50 \%$ improvement in American College of Rheumatology (ACR) criteria (ACR50) at week 24 (prespecified $\alpha=0.10$ ). Results At week 24, a significant dose-response relationship was observed using ACR50 ( $p=0.059)$ and ACR20 ( $p=0.044)$ response rates. Using modelestimated data, only $120 \mathrm{mg}$ had significantly higher ACR50 and ACR20 response rates versus placebo $(p<0.05)$. Observed response rates were significantly higher for $120 \mathrm{mg}$ versus placebo as measured by ACR50 at weeks $12(p=0.039)$ and $20(p=0.018)$, but not week 24, and by ACR20 at weeks $12(p=0.011)$ and $24(p=0.039)$. Mean DAS28 C-reactive protein improved with $120 \mathrm{mg}$ at week $24(p=0.048)$. Frequency of TEAEs was similar across groups (range $50-69 \%, p=0.884)$. Ten (8.2\%) tabalumab and $5(13.9 \%)$ placebo patients reported a serious adverse event (SAE). Infections occurred more frequently in patients exposed to tabalumab (30.3\% vs $19.4 \%)$. Serious infections were reported in $3(2.5 \%)$ tabalumab-treated patients only. Conclusions A dose-response relationship was detected with monthly subcutaneous tabalumab. A significant effect was detected with the $120 \mathrm{mg}$ dose with no unexpected safety signals.

Clinical Trial \# NCT00785928.

\section{INTRODUCTION}

Rheumatoid arthritis (RA) affects approximately $1 \%$ of the population ${ }^{1}$ and is characterised by joint inflammation that can lead to joint destruction and systemic complications. ${ }^{2}$ Currently available biologic therapies selectively target key molecules associated with joint inflammation, but approximately $30 \%$ of patients will remain unresponsive to these treatments. ${ }^{3}$

B-cell activating factor (BAFF) is a tumour necrosis factor (TNF) family ligand that is increased in the sera and synovial fluid of patients with RA, ${ }^{4-6}$ and is required for B-cell survival. ${ }^{7}$ BAFF has two biologically active forms, a soluble and membrane-bound form, ${ }^{8}$ and induces polyclonal maturation of immature and mature B cells involved in RA pathogenesis. 910

Tabalumab is a human monoclonal antibody that neutralises soluble and membrane-bound BAFF ${ }^{11}$ In a previous study, intravenous tabalumab (30, 60 and $160 \mathrm{mg}$ ) reduced RA signs and symptoms in patients with an inadequate response to methotrexate (MTX-IR); although all doses were effective, no dose-response relationship in American College of Rheumatology (ACR) scores was observed. ${ }^{12}$

The current trial, which used Bayesian-adaptive randomisation, explored the dose-response relationship of tabalumab given subcutaneously once every 4 weeks (Q4W) to patients with active RA receiving stable doses of MTX.

\section{METHODS}

\section{Patients}

Patients were recruited from 64 centres in 12 countries (Argentina, Australia, Chile, Germany, Hungary, India, Mexico, Poland, Romania, Slovakia, Ukraine and the USA). All patients provided voluntary written informed consent. The study was approved by local Institutional Review Boards in accordance with the Declaration of Helsinki and applicable laws and regulations.

Patients were aged between 18 and 75 years, were taking MTX (10-25 mg/week) for $\geq 16$ weeks, and met ACR (1987 revised) criteria for RA. ${ }^{13}$ Major inclusion criteria included $\geq 5 / 28$ swollen and $\geq 5 / 28$ tender joints; ACR functional class I, II, or III; a history of, or a current, positive rheumatoid factor $(\mathrm{RF}+)$ test; a C-reactive protein $(\mathrm{CRP}) \geq 1.2$ times upper limit of normal (ULN; $1.0 \mathrm{mg} / \mathrm{dl}$ ); and the absence of pregnancy or breast feeding.

Major exclusion criteria included use of any parenteral or oral corticosteroid at $>10 \mathrm{mg}$ /day of prednisone or its equivalent within 4 weeks of 
baseline; use of any B-cell biotherapies at any time; insufficient response to a TNF inhibitor (TNF-IR; patients who stopped for reasons other than lack of efficacy were eligible); presence of other autoimmune disorders; a positive protein derivative test for tuberculosis; or serious bacterial infections within 6 months of enrolment. Study participants must have discontinued etanercept $\geq 28$ days before baseline, and infliximab, adalimumab, or other biologic TNF inhibitors $\geq 56$ days before baseline.

\section{Study design}

This was a phase 2, 24-week, double-blind, placebo-controlled, dose-ranging study. Following two screening visits, patients were randomised by Bayesian-adaptive method ${ }^{14}$ to receive placebo or tabalumab (1, 3, 10, 30, 60, or $120 \mathrm{mg}$ ) subcutaneously Q4W for 24 weeks (figure 1A). Patients maintained their prestudy stable dose of MTX and received their other usual medical treatments for RA or concomitant diseases as allowed by protocol.

Bayesian-adaptive randomisation used accumulating data from the ongoing trial to make progressive adjustments in dose-group assignments. Over time, these adjustments were expected to provide a more precise estimate of the dose-response relationship. Computer-generated random treatment assignments were made using an interactive voice-response system (IVRS). The first 35 patients were randomised to 1 of 7 treatment groups in equal number. Once 35 patients were randomised, there was a constant $20 \%$ chance of randomisation to placebo and an $80 \%$ chance of randomisation to one of the tabalumab doses. A contract research organisation periodically updated a non-informative, normal, dynamic linear model prior distribution, from which the posterior distribution of a 24-week, treatment-response model was derived. The posterior distribution was used to adjust the probability of randomisation to each tabalumab dose. As the study progressed, the probability of assignment to higher doses increased. Enrolment and randomisation ended when approximately 150 patients had been randomised. These 150 patients provided $80 \%$ power to detect a difference based on simulations using varying responses-to-dose assumptions as well as varying patient accrual and dropout rates.

A

A

Tabalumab $1 \mathrm{mg}(\mathrm{n}=30)$
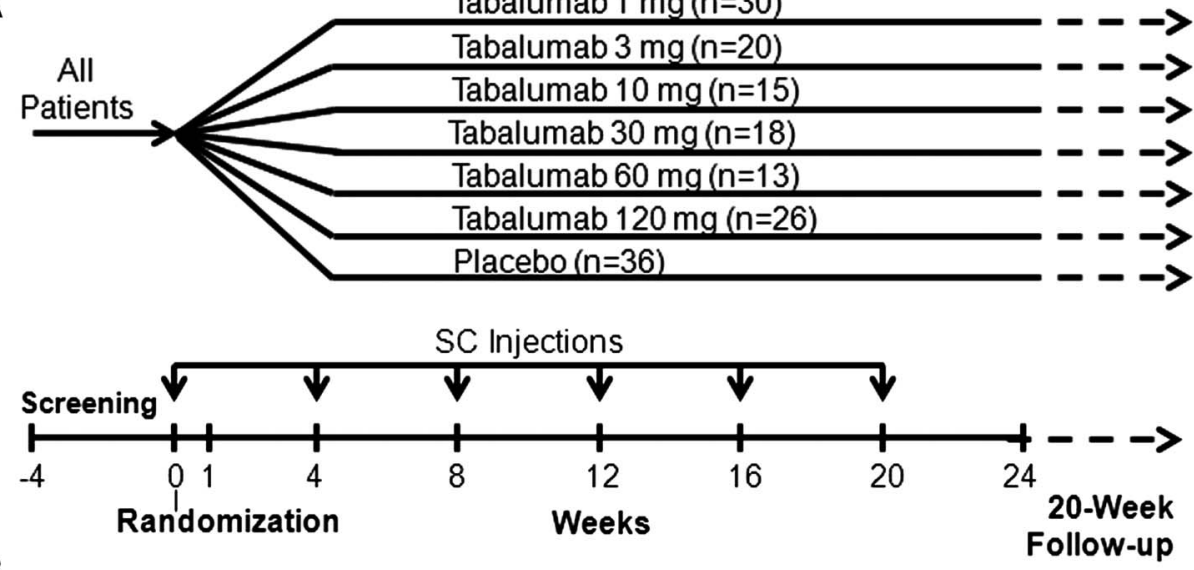

B

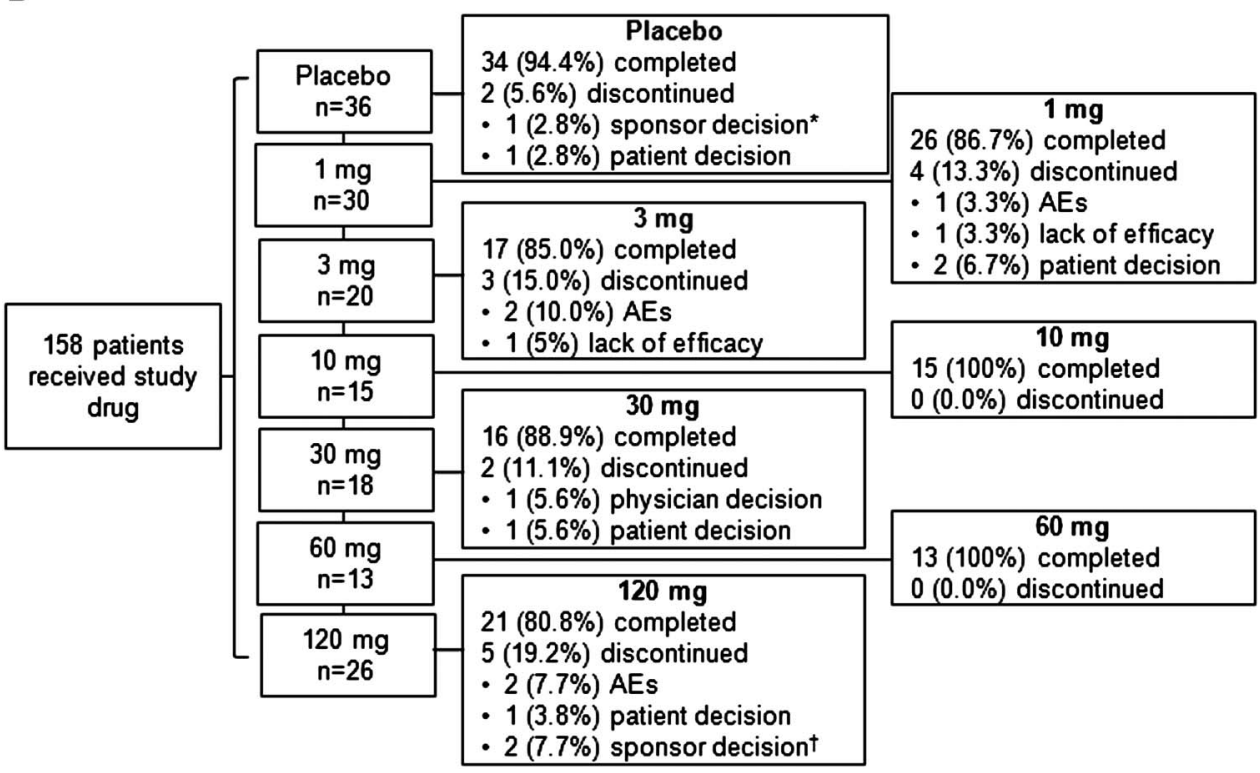

Figure 1 Study design and patient disposition. (A) Patients were adaptively randomised by Bayesian method. Over time, the probability of randomisation to more effective doses increased, resulting in unequal distribution of patients across groups. Study drug was administered six times by SC injection for 24 weeks. (B) Disposition of 158 randomised and treated patients through week 24. The percentage of patients who withdrew from the study and reasons for discontinuation are also shown for each group. ${ }^{*}$ One patient in the placebo group was discontinued due to elevated liver enzymes at the sponsor's request. †Two patients in the $120 \mathrm{mg}$ group were excluded from primary efficacy analyses due sponsor decision to withdraw a site for violation of good clinical practices. AEs, adverse events, SC, subcutaneous. 


\section{Endpoints}

The primary endpoint was to test for a significant dose-response relationship based on a statistical model of the proportion of patients having $\geq 50 \%$ improvement in ACR criteria (ACR50) at week 24. Key secondary efficacy endpoints included the dose-response relationship based on modelled ACR20 response rates at week 24; ACR20 and ACR50 response rates, change in DAS28, and percent change in CRP at each visit (weeks 1, 4, 8, 12, 16, 20 and 24); and pharmacokinetic parameters. Safety endpoints included incidences of adverse events (AEs) and serious adverse events (SAEs), and clinical laboratory test and immunogenicity results. Pharmacodynamic endpoints included changes over time in serum immunoglobulins (IgM, IgG, IgA), total B cells (CD20), and B-cell subsets (mature naïve (CD19, IgD+, CD27-), memory (CD19, IgD-, CD27)).

All efficacy measures used 28-joint counts and CRP for response calculations. Blood samples were collected at baseline and subsequent visits for determining serum tabalumab concentrations (weeks 1, 4, 8, 12, 16, 20 and 24), serum immunoglobulins (IgG, IgM and $\operatorname{IgA}$ ) (weeks 1, 4, 16 and 24), and antitabalumab antibodies (weeks 4, 8 and 24). Serum tabalu$\mathrm{mab}$ and immunoglobulin concentrations were assayed using validated methods. B cells were assayed by flow cytometry. ${ }^{15}$

Standard laboratory tests, including chemistry, haematology, urinalysis panels and ECGs were obtained at regular intervals. Vital signs were taken, and AEs and SAEs were recorded and summarised at each visit.

\section{Statistical methods}

All analyses were performed with the intent-to-treat population (all randomised patients who received $\geq 1$ dose of study drug). Two $120 \mathrm{mg}$ patients were excluded from primary efficacy analyses (site withdrawn due to good clinical practices violation). For ACR analyses, non-responder imputations (NRIs) were used for patients who discontinued early. For all other efficacy analyses, a last-observation-carried-forward (LOCF) approach was used.

The primary analysis tested for a significant ACR50 doserelated response over doses ranging from placebo to $120 \mathrm{mg}$ tabalumab at week 24. The dose-response relationship was tested with a joint test of linear and quadratic dose response (regression model included terms for dose and dose $^{2}$ ) from the likelihood ratio test $(\alpha=0.10)$. The smallest dose achieving $\geq 95 \%$ of maximal efficacy $\left(\mathrm{ED}_{95}\right)$ and ACR50 response rates corresponding to each dose were estimated from the logistic regression model. This analysis was repeated for ACR20. The dose-response relationship for DAS28 was performed by Spearman non-parametric correlations with dose (1-sided, $\alpha=0.05)$.

ACR20 and ACR50 responses were summarised, and Fisher exact tests compared tabalumab observed response rates with placebo at all timepoints. Modelled response rates were compared using a 1-sided, $\mathrm{z}$ test with SE estimated using the delta method. For DAS28, pairwise comparisons of tabalumab doses versus placebo were performed using contrast statements within an analysis of covariance (ANCOVA) model with treatment as the fixed factor and baseline as a covariate. Pairwise comparisons were 1 -sided ( $\alpha=0.05)$.

Pharmacodynamic analyses were performed by 2 -sided comparisons of all tabalumab doses combined versus placebo, using ranked ANCOVA with the standardised rank outcome variable, treatment as the fixed factor, and the standardised rank baseline value as a covariate $(\alpha=0.10)$. For CRP and serum immunoglobulins, 2-sided pairwise comparisons of tabalumab dose versus placebo were performed using contrast statements within ANCOVA $(\alpha=0.10)$.

Tabalumab pharmacokinetic parameters were analysed using a population approach implemented with NONMEM (ICON Development Solutions, Ellicott City, Maryland, USA). Clearance and distribution volume were characterised as a function of dose and treatment duration.

Safety data were descriptively summarised by treatment. Placebo and tabalumab doses were compared using a $\chi^{2}$ test, or Fisher exact test if $\chi^{2}$ assumptions were violated, for any event.

\section{RESULTS}

\section{Patient disposition and characteristics}

A total of $142 / 158$ patients (89.9\%) completed: $34 / 36(94.4 \%)$ in the placebo group and $108 / 122(88.5 \%)$ in all tabalumab groups combined (figure $1 \mathrm{~B}$ ). The most common reasons for early withdrawal were AEs and patient decision (figure 1B).

Overall, baseline characteristics were similar across groups with a few exceptions (table 1). In the $60 \mathrm{mg}$ group, a smaller percentage were Caucasian (39\%; range $53-73 \%, p=0.049$ vs placebo). The placebo group had shorter disease duration than the $30 \mathrm{mg}$ group ( $p=0.001)$. Baseline disease activity parameters and average MTX and prednisone doses were comparable across groups. Eleven patients had prior TNF-inhibitor exposure: 7 placebo (infliximab, $\mathrm{n}=2$; adalimumab, $\mathrm{n}=2$; investigational drug, $\mathrm{n}=1$; etanercept, $\mathrm{n}=2$ ), one $1 \mathrm{mg}$ (infliximab), one $30 \mathrm{mg}$ (etanercept), one $60 \mathrm{mg}$ (infliximab), and one $120 \mathrm{mg}$ tabalumab (investigational drug).

\section{Clinical response}

A significant (prespecified $\alpha=0.10$ ) dose-response relationship was detected for ACR50 $(p=0.059)$ and ACR20 $(p=0.044)$ at week 24 using a regression model. The $\mathrm{ED}_{95}$ was $119.0 \mathrm{mg}$ and $118.5 \mathrm{mg}$ for ACR50 and ACR20, respectively.

Modelled and observed results for ACR50 and ACR20 responders at week 24 are presented in table 2 . Using model-estimated data at week 24 , only the $120 \mathrm{mg}$ dose had significantly higher ACR50 and ACR20 response rates versus placebo (table 2).

The observed ACR50 response rate (NRI) was significantly higher with only the $120 \mathrm{mg}$ dose versus placebo at week 12 $(33.3 \%(8 / 24)$ vs $11.1 \%(4 / 36) ; p=0.039)$ and week $20(33.3 \%$ $(8 / 24)$ vs $8.3 \%(3 / 36) ; p=0.018)$, but not at week 24 (table 2 , figure $2 \mathrm{~A}$ ). The ACR20 response rate (NRI) was significantly higher with $120 \mathrm{mg}$ versus placebo at week $12(66.7 \%(16 / 24)$ vs $33.3 \%(12 / 36) ; p=0.011$ ), and week 24 (table 2 , figure $2 B$ ). No other dose was significantly different from placebo at any timepoint for ACR20, except $60 \mathrm{mg}$ at week $4(38.5 \%$ (5/13) vs $11.1 \%(4 / 36) ; p=0.043)$ (figure $2 B$ ).

At baseline, DAS28 scores were similar across groups (table 1). DAS28 score significantly improved from baseline with 120 mg versus placebo at week 24 (table 2); this improvement was also observed at earlier timepoints (figure 2C). No other dose showed a significant DAS28 improvement.

At week 24, tender joint counts, swollen joint counts, and patient's assessments of disease activity and pain were similar across groups, whereas physician's assessment of disease activity was significantly reduced with $120 \mathrm{mg}$ (table 3). Mean CRP was similar between placebo and tabalumab groups at week 24 . In some patients, elevated CRP at screening was no longer elevated at baseline. A posthoc analysis of patients with baseline CRP $>$ ULN was conducted by treatment group (placebo, 1, 3, 10, 30, 60 and $120 \mathrm{mg}$ ). For these groups, baseline CRP was $38.1,27.0,45.0,38.4,30.5,37.4$ and $30.2 \mathrm{mg} / \mathrm{dl}$, and mean CRP 
Table 1 Baseline demographics and clinical parameters (ITT population)

\begin{tabular}{|c|c|c|c|c|c|c|c|}
\hline & \multirow[b]{2}{*}{ Placebo $(\mathrm{N}=36$ ) } & \multicolumn{6}{|l|}{ Tabalumab } \\
\hline & & $1 \mathrm{mg}(\mathrm{N}=30)$ & $3 \mathrm{mg}(\mathrm{N}=20)$ & $10 \mathrm{mg}(\mathrm{N}=15)$ & $30 \mathrm{mg}(\mathrm{N}=18)$ & $60(\mathrm{mg} \mathrm{N}=13)$ & $120 \mathrm{mg}(\mathrm{N}=26)$ \\
\hline \multicolumn{8}{|l|}{ Gender, n (\%) } \\
\hline Female & $30(83.3)$ & $26(86.7)$ & $14(70.0)$ & $12(80.0)$ & $15(83.3)$ & $12(92.3)$ & $18(69.2)$ \\
\hline Age, years & $50.6 \pm 11.7$ & $54.6 \pm 11.7$ & $53.4 \pm 10.8$ & $51.2 \pm 13.8$ & $54.5 \pm 11.8$ & $44.4 \pm 13.8$ & $50.7 \pm 12.0$ \\
\hline \multicolumn{8}{|l|}{ Race/ethnicity, n (\%) } \\
\hline East Asian & $2(5.6)$ & $2(6.7)$ & $1(5.0)$ & 0 & $1(5.6)$ & $3(23.1)$ & $1(3.8)$ \\
\hline West Asian & 0 & 0 & 0 & $1(6.7)$ & 0 & 0 & 0 \\
\hline African & $1(2.8)$ & $1(3.3)$ & 0 & 0 & 0 & 0 & 0 \\
\hline Disease duration, years & $6.2 \pm 7.2$ & $9.3 \pm 7.9$ & $8.4 \pm 7.0$ & $9.0 \pm 6.7$ & $11.7 \pm 7.0^{*}$ & $10.1 \pm 9.3$ & $9.9 \pm 11.6$ \\
\hline CRP above ULN at baseline, $\mathrm{n}(\%)$ & $28(77.8)$ & $21(70.0)$ & $15(75.0)$ & $12(80.0)$ & $15(83.3)$ & $12(92.3)$ & $19(73.1)$ \\
\hline CD20 B-cell counts, cells/ $\mu$ l & $193.4 \pm 130.3$ & $220.8 \pm 133.2$ & $208.1 \pm 171.8$ & $189.5 \pm 64.1$ & $220.1 \pm 181.6$ & $212.5 \pm 122.1$ & $187.4 \pm 110.0$ \\
\hline
\end{tabular}

All values are mean $\pm S D$, unless otherwise noted.

${ }^{*} \mathrm{p}<0.05$ versus placebo.

CRP, C reactive protein; CRP; HAQ-DI, Health Assessment Questionnaire-Disability Index; DAS28-CRP, Disease Activity Score based on 28-joint count; ITT, Intent-to-treat population; MTX, methotrexate; ULN, upper limit of normal.

(LOCF) at week 24 was 16.8, 8.1, -8.8, 21.8, 46.2, 38.9 and $38.5 \mathrm{mg} / \mathrm{dl}$, respectively.

\section{Pharmacokinetics}

Serum tabalumab concentrations demonstrated non-linear elimination. The time to reach maximum concentration following subcutaneous injection at steady state $\left(\mathrm{T}_{\mathrm{max}, \mathrm{ss})}\right.$ and the half-life over the 4-week dosing interval $\left(t_{1 / 2, \text { tau }}\right)$ increased with increasing dose. At $120 \mathrm{mg}, \mathrm{T}_{\text {max,ss }}$ and $\mathrm{t}_{1 / 2 \text {,tau }}$ were 5.0 and 21.6 days, respectively.

\section{Biologic activity}

CD20 B-cell counts across all tabalumab doses initially increased at week 1 (mean change in all doses combined vs placebo: 67.75 vs 14.64 cells/ $\mu 1, p<0.001)$ and subsequently decreased back to baseline or below it starting from week 4 (15.03 vs 6.91 cells $/ \mu 1, p=0.371$ ) and continuing through week
24 (-34.56 vs 17.63 cells $/ \mu \mathrm{l}, \mathrm{p}=0.008)$. Of the CD19 cell subsets, only mature, naïve cell counts showed a pattern similar to CD20 cells (week 1: 38.17 vs 15.70 cells $/ \mu 1, p=0.024$; week 24: -45.63 vs 18.06 cells $/ \mu 1, p<0.001)$. Increases in memory cell counts from baseline were observed across groups over 24 weeks, with the largest increases in the higher dose groups. At week 24 , only $30 \mathrm{mg}(p=0.006), 60 \mathrm{mg}(\mathrm{p}=0.003)$ and $120 \mathrm{mg}(\mathrm{p}<0.001)$ demonstrated statistically significant increases in memory B cells versus placebo.

Mean IgM and IgA levels tended to be lower than baseline for all tabalumab groups at weeks 16 and 24. For IgM, this difference was statistically significant at week 16 with the 30 $\mathrm{mg} \quad(-0.15 \pm 0.40 \mathrm{~g} / \mathrm{l}, \quad \mathrm{p}=0.016), 60 \mathrm{mg} \quad(-0.24 \pm 0.27 \mathrm{~g} / \mathrm{l}$, $\mathrm{p}=0.028)$, and $120 \mathrm{mg}(-0.17 \pm 0.32 \mathrm{~g} / \mathrm{l}, \mathrm{p}=0.005)$ versus placebo $(0.02 \pm 0.39 \mathrm{~g} / \mathrm{l})$, and at week 24 with $30 \mathrm{mg}(-0.08 \pm 0.53 \mathrm{~g} / \mathrm{l}$, $\mathrm{p}=0.023), 60 \mathrm{mg}(-0.30 \pm 0.30 \mathrm{~g} / \mathrm{l}, \mathrm{p}=0.004)$, and $120 \mathrm{mg}$ $(-0.09 \pm 0.38 \mathrm{~g} / \mathrm{l}, \mathrm{p}=0.017)$ versus placebo $(0.02 \pm 0.32 \mathrm{~g} / \mathrm{l})$. For

Table 2 Summary of efficacy endpoints at week 24

\begin{tabular}{|c|c|c|c|c|c|c|c|c|}
\hline & \multirow[b]{2}{*}{ Placebo $(\mathrm{N}=36)$} & \multicolumn{6}{|l|}{ Tabalumab } & \multirow[b]{2}{*}{ p Value } \\
\hline & & $1 \mathrm{mg}(\mathrm{N}=30)$ & $3 \mathrm{mg}(\mathrm{N}=20)$ & $10 \mathrm{mg}(\mathrm{N}=15)$ & $30 \mathrm{mg}(\mathrm{N}=18)$ & $60 \mathrm{mg}(\mathrm{N}=13)$ & $120 \mathrm{mg}(\mathrm{N}=24)$ & \\
\hline ACR50 obs, $n(\%)(p)^{*} \dagger$ & $8(22.2)$ & $3(10.0)(0.896)$ & $2(10.0)(0.940)$ & $5(33.3)(0.311)$ & $2(11.1)(0.919)$ & $1(7.7)(0.954)$ & $9(37.5)(0.255)$ & NA \\
\hline ACR50 model, $\%(p){ }^{*} \dagger$ & 18.1 & $17.7(0.827)$ & $17.0(0.828)$ & $15.0(0.833)$ & $11.8(0.834)$ & $11.8(0.767)$ & $37.0(0.037)$ & $(0.059) \ddagger$ \\
\hline ACR20 obs, n (\%) (p) *† & $16(44.4)$ & $12(40.0)(0.730)$ & $9(45.0)(0.594)$ & $7(46.7)(0.563)$ & $11(61.1)(0.193)$ & $7(53.8)(0.397)$ & $17(70.8)(0.039)$ & NA \\
\hline ACR20 model, $\%(p){ }^{*} \dagger$ & 43.2 & $43.6(0.171)$ & $44.3(0.170)$ & $46.9(0.162)$ & $53.5(0.132)$ & $61.5(0.070)$ & $70.1(0.005)$ & $(0.044) \ddagger$ \\
\hline $\begin{array}{l}\text { DAS28, mean } \pm \text { SD } \\
\text { change from baseline }(p) \S \Phi\end{array}$ & $-1.5 \pm 1.3$ & $-1.5 \pm 1.3(0.457)$ & $-1.0 \pm 1.1(0.874)$ & $-1.7 \pm 1.0(0.278)$ & $-1.5 \pm 1.3(0.357)$ & $-1.6 \pm 1.2(0.271)$ & $-1.9 \pm 1.2(0.048)$ & $(0.071)^{* *}$ \\
\hline
\end{tabular}

*1-sided Fisher exact test that the tabalumab group has more responders than placebo.

tImputed by non-responder imputation.

łLikelihood ratio test of quadratic logistic regression model, testing the existence of a dose-response with a prespecified 2-sided type 1 error rate of 0.10 .

§1-sided pairwise comparison using contrast statements with an analysis of covariance (ANCOVA) model with treatment as the fixed factor and baseline as the covariate.

Ilmputed by last-observation-carried-forward.

**Dose-response relationship from 1-sided Spearman non-parametric correlation analysis.

ACR50, American College of Rheumatology 50 responder index; ACR20, American College of Rheumatology 20 responder index; DAS28, Disease Activity Score based on 28-joint count; obs, actual observations; model, assessed using a statistical model; NA, not available; $p, p$ Value. 


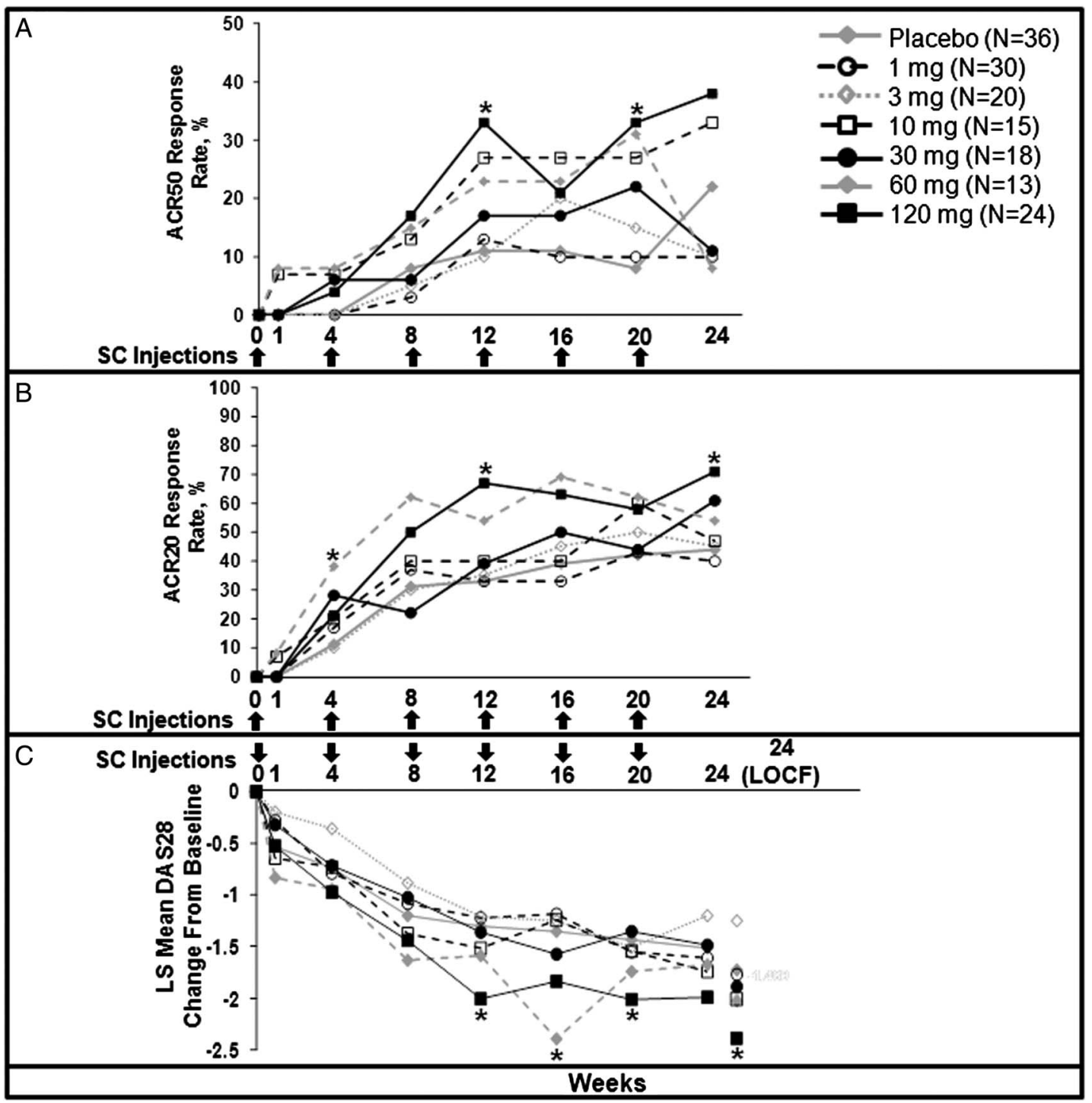

Figure 2 (A) Values are observed changes in the ACR50 response rate at each treatment visit with the tabalumab dose or placebo; non-responders imputed. $p$ Values are based on 1-sided Fisher exact test that the tabalumab group has more responders than placebo. ${ }^{*} p \leq 0.05$ Versus placebo. (B) Values are observed changes in the ACR20 response rate at each treatment visit with the tabalumab dose or placebo; non-responders imputed. $p$ Values are based on 1-sided Fisher exact test that the tabalumab group has more responders than placebo. * $\mathrm{p} \leq 0.05$ Versus placebo. (C) Time course of LS mean change in DAS28 score at each treatment visit with the tabalumab dose or placebo. $p$ Values are based on 1-sided pairwise comparison of the tabalumab dose level versus placebo using contrast statements within an ANCOVA model with treatment as the fixed factor and the baseline value as a covariate. ${ }^{*} p \leq 0.05$ Versus placebo. ACR20, proportion of responders having $\geq 20 \%$ improvement according to American College of Rheumatology (ACR) criteria; ACR50, proportion of patients having $\geq 50 \%$ improvement according to ACR criteria; ANCOVA, analysis of covariance; DAS28, Disease Activity Score based on 28-joint count; LOCF, last-observation-carried-forward, LS mean, least squares mean; SC, subcutaneous.

IgA, this difference was statistically significant at week 16 , with $120 \mathrm{mg}$ versus placebo $(-0.32 \pm 0.42$ vs $-0.12 \pm 0.50 \mathrm{~g} / \mathrm{l}$, $\mathrm{p}=0.040)$, and at week 24 with $60 \mathrm{mg}(-0.42 \pm 0.45 \mathrm{~g} / \mathrm{l}$, $\mathrm{p}=0.025)$ and $120 \mathrm{mg}(-0.25 \pm 0.63 \mathrm{~g} / \mathrm{l}, \mathrm{p}=0.030)$ versus placebo $(-0.12 \pm 0.48 \mathrm{~g} / \mathrm{l})$. Mean IgG levels were not significantly different from placebo with any tabalumab dose at any timepoint. There was no association between changes in serum immunoglobulin levels and occurrence of infection or other AEs. There was no correlation between clinical response, B-cell counts, or serum immunoglobulin levels.

\section{Safety}

The frequency of treatment-emergent adverse events (TEAEs) was similar across tabalumab doses (range 50-69\%, p=0.884) (table 4). The majority of TEAEs were mild or moderate in severity with no obvious trends in the nature or frequency by dose. The most frequently reported TEAEs were injection-site pain and upper respiratory tract infection (table 4). Five patients discontinued due to an AE, all of whom were treated with tabalumab $1 \mathrm{mg}$ (hemiplegia), $3 \mathrm{mg}$ (prolonged OT and RA worsening (exacerbation/flare)), or $120 \mathrm{mg}$ (diverticulitis and RA worsening). The incidence of SAEs was $13.9 \%(5 / 36$ patients) with placebo and ranged from $3.8 \%$ (1/26 patients) with $120 \mathrm{mg}$ to $16.7 \%$ (3/18 patients) with $30 \mathrm{mg}$ (table 4). RA worsening was the only SAE reported in $>1$ patient $(n=2$, placebo). No patients died during the study.

Infection was reported at a higher incidence with tabalumab (30.3\% (37/122 patients)) than placebo (19.4\% (7/36 patients)), but did not increase with higher doses. The lowest incidence of infection was observed with $120 \mathrm{mg}(11.5 \%)$. Serious infections 
Table 3 Composite score components at baseline and at week 24 (LOCF)

\begin{tabular}{|c|c|c|c|c|c|c|c|}
\hline & \multirow[b]{2}{*}{ Placebo $(\mathrm{N}=36)$} & \multicolumn{6}{|l|}{ Tabalumab } \\
\hline & & $1 \mathrm{mg}(\mathrm{N}=30)$ & $3 \mathrm{mg}(\mathrm{N}=20)$ & $10 \mathrm{mg}(\mathrm{N}=15)$ & $30 \mathrm{mg}(\mathrm{N}=18)$ & $60 \mathrm{mg}(\mathrm{N}=13)$ & $120 \mathrm{mg}(\mathrm{N}=24)$ \\
\hline \multicolumn{8}{|c|}{ Swollen joint count (28) } \\
\hline Baseline & $12.0 \pm 5.5$ & $13.4 \pm 5.8$ & $11.2 \pm 5.0$ & $15.4 \pm 6.3$ & $12.7 \pm 5.6$ & $13.1 \pm 5.4$ & $11.9 \pm 6.1$ \\
\hline Week 24 & $6.3 \pm 4.7$ & $6.5 \pm 5.5$ & $5.5 \pm 5.8$ & $6.5 \pm 5.3$ & $7.3 \pm 7.6$ & $6.9 \pm 4.8$ & $4.3 \pm 3.5$ \\
\hline \multicolumn{8}{|c|}{ Tender joint count (28) } \\
\hline Baseline & $16.0 \pm 6.5$ & $17.8 \pm 7.2$ & $16.5 \pm 6.3$ & $16.5 \pm 8.3$ & $15.4 \pm 5.8$ & $15.2 \pm 6.3$ & $13.7 \pm 6.3$ \\
\hline Week 24 & $8.9 \pm 6.7$ & $10.5 \pm 9.9$ & $12.0 \pm 9.6$ & $7.8 \pm 5.9$ & $7.7 \pm 6.9$ & $7.8 \pm 7.4$ & $6.2 \pm 5.9$ \\
\hline \multicolumn{8}{|c|}{ Physician's global assessment of disease activity } \\
\hline Baseline & $61.8 \pm 16.6$ & $61.5 \pm 20.2$ & $57.9 \pm 16.5$ & $67.2 \pm 14.6$ & $59.9 \pm 16.8$ & $53.0 \pm 13.7$ & $61.6 \pm 14.8$ \\
\hline Week 24 & $39.0 \pm 23.7$ & $38.7 \pm 24.3$ & $31.7 \pm 22.5$ & $37.0 \pm 22.3$ & $31.6 \pm 21.7$ & $31.6 \pm 20.8$ & $25.8 \pm 14.2^{*}$ \\
\hline \multicolumn{8}{|c|}{ Patient's global assessment of disease activity } \\
\hline Baseline & $70.3 \pm 19.4$ & $71.6 \pm 17.5$ & $66.8 \pm 18.3$ & $61.6 \pm 20.8$ & $64.5 \pm 24.3$ & $60.9 \pm 20.1$ & $69.4 \pm 15.0$ \\
\hline Week 24 & $46.1 \pm 26.2$ & $50.9 \pm 27.5$ & $50.8 \pm 21.2$ & $39.1 \pm 28.4$ & $45.9 \pm 23.7$ & $45.5 \pm 17.3$ & $35.6 \pm 20.2$ \\
\hline \multicolumn{8}{|c|}{ Patient's global assessment of pain } \\
\hline Baseline & $66.3 \pm 23.7$ & $66.4 \pm 20.2$ & $63.1 \pm 18.4$ & $61.5 \pm 23.4$ & $59.5 \pm 23.7$ & $64.4 \pm 16.1$ & $66.2 \pm 15.3$ \\
\hline Week 24 & $46.8 \pm 25.6$ & $48.6 \pm 26.1$ & $50.4 \pm 20.8$ & $40.3 \pm 28.6$ & $46.4 \pm 25.3$ & $46.8 \pm 16.9$ & $36.4 \pm 21.0$ \\
\hline \multicolumn{8}{|l|}{ CRP, mg/dl } \\
\hline Baseline & $3.1 \pm 2.5$ & $2.1 \pm 1.5$ & $3.5 \pm 3.8$ & $3.3 \pm 2.2$ & $2.7 \pm 2.2$ & $3.5 \pm 3.2$ & $2.5 \pm 2.9$ \\
\hline Week 24 & $2.2 \pm 1.8$ & $1.8 \pm 1.4$ & $3.5 \pm 3.1$ & $2.7 \pm 1.3$ & $1.8 \pm 1.9$ & $1.5 \pm 0.9$ & $1.7 \pm 1.3$ \\
\hline
\end{tabular}

All values are mean \pm SD. Analyses are 2-sided pairwise comparisons of tabalumab dose versus placebo were performed using contrast statements within ANCOVA. ${ }^{*} \mathrm{p}<0.05$ versus placebo.

CRP, C-reactive protein; LOCF, last-observation-carried-forward; $p, p$ Value.

were reported in three $(2.5 \%)$ tabalumab-treated patients. One patient discontinued due to a serious infectious event of $\mathrm{H} 1 \mathrm{~N} 1$ influenza pneumonia 24 days after a single $30 \mathrm{mg}$ dose.

No clinically relevant differences or trends were identified in vital signs, ECG, or chemistry, haematology and urinalysis panels. The percentage of patients with abnormal laboratory values was comparable across groups, with no apparent trends.

\section{Immunogenicity}

At 24 weeks, two tabalumab-treated patients had treatmentemergent antitabalumab antibodies (TEAb (fourfold increase from baseline); $1 \mathrm{mg}$ and $120 \mathrm{mg}$ group). One patient seroconverted at week 4 , the other at week 8 , and TEAb persisted to week 24 . None were neutralising. Two additional patients (1 $\mathrm{mg}$ and $10 \mathrm{mg}$ group) and 2 placebo patients had transient $\mathrm{TEAb}$ detected at a single sampling. One placebo patient had neutralising antibodies at week 24 . The presence of TEAb did not appear to have an effect on ACR response. None of the tabalumab-treated patients who tested positive for antibodies experienced an SAE or serious infection, nor did they discontinue due to lack of efficacy. There was no discernible reduction in tabalumab serum concentrations in the presence of antitabalumab antibodies and no dose-related trends.

Table 4 Overview of adverse events at week 24

\begin{tabular}{|c|c|c|c|c|c|c|c|c|}
\hline \multirow[b]{2}{*}{ Number of patients (\%) } & \multirow[b]{2}{*}{$\begin{array}{l}\text { Placebo } \\
(\mathrm{N}=36)\end{array}$} & \multicolumn{6}{|c|}{ Tabalumab } & \multirow[b]{2}{*}{$\begin{array}{l}\text { All tabalumab doses } \\
\text { combined }(\mathrm{N}=122)\end{array}$} \\
\hline & & $\begin{array}{l}1 \mathrm{mg} \\
(\mathrm{N}=30)\end{array}$ & $\begin{array}{l}3 \mathrm{mg} \\
(\mathrm{N}=20)\end{array}$ & $\begin{array}{l}10 \mathrm{mg} \\
(\mathrm{N}=15)\end{array}$ & $\begin{array}{l}30 \mathrm{mg} \\
(\mathrm{N}=18)\end{array}$ & $\begin{array}{l}60 \mathrm{mg} \\
(\mathrm{N}=13)\end{array}$ & $\begin{array}{l}120 \mathrm{mg} \\
(\mathrm{N}=26)\end{array}$ & \\
\hline Deaths & 0 & 0 & 0 & 0 & 0 & 0 & 0 & 0 \\
\hline SAEs & $5(13.9)$ & $4(13.3)$ & 0 & 0 & $3(16.7)$ & $2(15.4)$ & $1(3.8)$ & $10(8.2)$ \\
\hline $\begin{array}{l}\text { Patients who discontinued due to } \\
\text { an } A E\end{array}$ & 0 & $1(3.3)$ & $2(10.0)$ & 0 & 0 & 0 & $2(7.7)$ & $5(4.1)$ \\
\hline TEAEs & $22(61.1)$ & $20(66.7)$ & $12(60)$ & $9(60)$ & $12(66.7)$ & $9(69.2)$ & $13(50)$ & $75(61.5)$ \\
\hline \multicolumn{9}{|c|}{ TEAEs that occurred in $\geq 3 \%$ of patients in the combined tabalumab group } \\
\hline Injection-site pain & 0 & $1(3.3)$ & 0 & $4(26.7)$ & $1(5.6)$ & $1(7.7)$ & $2(7.7)$ & $9(7.4)$ \\
\hline Upper respiratory tract infection & $1(2.8)$ & $3(10.0)$ & 0 & $3(20.0)$ & 0 & $2(15.4)$ & $1(3.8)$ & $9(7.4)$ \\
\hline RA worsening & $7(19.4)$ & $3(10.0)$ & $2(10.0)$ & 0 & 0 & 0 & $1(3.8)$ & $6(4.9)$ \\
\hline Hypertension & 0 & $1(3.3)$ & $1(5.0)$ & 0 & $1(5.6)$ & 0 & $2(7.7)$ & $5(4.1)$ \\
\hline Anemia & 0 & $1(3.3)$ & $2(10.0)$ & $1(6.7)$ & 0 & $1(7.7)$ & 0 & $5(4.1)$ \\
\hline Pharyngitis & 0 & 0 & $1(5.0)$ & $1(6.7)$ & $1(5.6)$ & 0 & $1(3.8)$ & $4(3.3)$ \\
\hline Pyrexia & $1(2.8)$ & $2(6.7)$ & $1(5.0)$ & 0 & 0 & 0 & $1(3.8)$ & $4(3.3)$ \\
\hline Urinary tract infection & $1(2.8)$ & $1(3.3)$ & $2(10.0)$ & $1(6.7)$ & 0 & 0 & 0 & $4(3.3)$ \\
\hline Weight increased & 0 & $1(3.3)$ & $1(5.0)$ & 0 & $1(5.6)$ & $1(7.7)$ & 0 & $4(3.3)$ \\
\hline Respiratory tract infection & 0 & $1(3.3)$ & $2(10.0)$ & 0 & 0 & $1(7.7)$ & 0 & $4(3.3)$ \\
\hline Nasopharyngitis & $2(5.6)$ & $2(6.7)$ & 0 & 0 & $2(11.1)$ & 0 & 0 & $4(3.3)$ \\
\hline
\end{tabular}

$\mathrm{AE}$, adverse event; RA, rheumatoid arthritis; SAEs, serious adverse events; TEAEs, treatment-emergent adverse events.

Percentages are based on the number of patients in each column. 


\section{DISCUSSION}

In the current study, which used Bayesian-adaptive randomisation, a statistically significant dose-response relationship was detected using regression models of ACR50 and ACR20 response rates at 24 weeks for tabalumab, administered monthly by subcutaneous injection over a $1 \mathrm{mg}$ to $120 \mathrm{mg}$ dose range. Significant efficacy versus placebo was detected with the $120 \mathrm{mg}$ dose for ACR50 (by regression analysis only), ACR20, and DAS28 at week 24.

The principles and potential utility of B-cell depletion in RA treatment have been recognised since 2001. ${ }^{16}$ Subsequent work resulted in the approval of rituximab for RA treatment in TNF-IR patients. ${ }^{17}$ The concept of effective RA treatment through B-cell inhibition (without profound depletion) has been explored with limited success. Belimumab, a monoclonal antibody that neutralises soluble BAFF, was studied but not developed as an RA treatment after modest phase 2 results. ${ }^{18} 19$ Atacicept, a fusion protein targeting BAFF and APRIL (a proliferation-inducing ligand), failed to achieve clinical benefits in two RA trials. ${ }^{20} 21$

Tabalumab neutralises membrane-bound and soluble BAFF and, thus, may have different biologic action and clinical outcomes than belimumab, atacicept and briobacept (a recombinant BAFF receptor immunoglobulin fusion protein). In an earlier study, intravenous tabalumab (30, 60 and $160 \mathrm{mg}$ ) administered every 3 weeks (O3W) for 6 weeks demonstrated clinical efficacy in biologic-naïve patients with RA. ${ }^{12}$ The present trial evaluated subcutaneous tabalumab across a wider range of doses given $\mathrm{Q} 4 \mathrm{~W}$ for 6 months. Adjusting for bioavailability and differences in dosing frequency, a subcutaneous Q4W 120 $\mathrm{mg}$ dose provides exposure equivalent to an intravenous $\mathrm{Q} 3 \mathrm{~W}$ $45 \mathrm{mg}$ dose (data not shown).

Overall, no unexpected safety signal was detected in this relatively small study; tabalumab had a consistent safety profile across dose groups and placebo. Infectious events were more frequent with tabalumab than placebo, although the frequency did not increase with higher doses. Mean IgM and IgA levels tended to be lower than baseline in all tabalumab groups in the later weeks of the study; changes from baseline were not associated with increases in AEs or infectious AEs.

Within 1 week of the first injection, CD20 B cells and CD19 mature, naive cells transiently increased with all tabalumab doses before decreasing back to baseline levels or below without profound reductions. Early increases in B cells with subsequent decreases have been observed with other BAFF-targeted therapies, such as briobacept ${ }^{22}$ and atacicept. ${ }^{23}$ No correlations were observed between B-cell changes and clinical efficacy or safety with tabalumab.

The following limitations of this study should be considered. Bayesian-adaptive randomisation was intended to estimate the dose-response relationship more precisely and to allocate patients to more effective dosing. However, patients were enrolled faster than planned, and updates to randomisation probabilities were not frequent enough. As a result, a higher percentage of patients were assigned to placebo or very low dose treatments. Despite this, a dose-response relationship was detected. Additionally, this was a short-term study with small treatment arms, and ACR50, rather than ACR20, was the primary endpoint. This study enrolled patients with active RA who were taking MTX, but not patients who previously failed TNF inhibitors or other biologic RA treatments, and only included RF+ patients. These findings cannot be generalised to patients on other background RA medications, with a history of exposure to a larger repertoire of agents, or who are seronegative. Despite these limitations, tabalumab demonstrated efficacy in MTX-IR patients.

In the present study, subcutaneous $120 \mathrm{mg}$ tabalumab appeared to reduce RA signs and symptoms in patients taking concomitant MTX. Overall, based on a limited number of exposures in this phase 2 study, tabalumab had no unexpected safety signals. After this study was completed, phase 3 clinical trials were undertaken using tabalumab in patients with RA. These trials were recently discontinued after interim analyses provided results that did not meet efficacy expectations. ${ }^{24} 25$ No safety concerns were noted.

Acknowledgements The authors would like to thank all the participating investigators. The authors would also like to thank Kelly Guerrettaz (PharmaNet/i3, an inVentiv Health Company) for writing assistance, and Pam Boltz (PharmaNet/i3, an inVentiv Health Company), Teri Tucker (PharmaNet/i3, an inVentiv Health Company), and Dr Pamela W Anderson (Eli Lilly and Company) for editorial assistance.

Contributors MCG contributed to the study design, was involved in the data analysis, and reviewed/edited the manuscript. EL participated as an investigator and reviewed/edited the manuscript. JS, MV, and DD contributed to the data analysis and reviewed/edited the manuscript. GS contributed to the study design. OB, SM, and P-YB contributed to the study design, implementation, and analysis, and reviewed/ edited the manuscript.

Funding This study was sponsored by Eli Lilly and Company.

Competing interests Mark Genovese has received grants and consulting fees from Eli Lilly and Company. Eric Lee has no competing interests to disclose. Julie Satterwhite, Melissa Veenhuizen, Damon Disch, Pierre-Yves Berclaz, Stephen Myers, and Olivier Benichou are employees and stockholders of Eli Lilly and Company.

Ethics approval IRB at each study site.

Provenance and peer review Not commissioned; externally peer reviewed.

\section{REFERENCES}

1. American College of Rheumatology Subcommittee on Rheumatoid Arthritis Guidelines. Guidelines for the management of rheumatoid arthritis: 2002 Update. Arthritis Rheum 2002; 46:328-46.

2. Klareskog L, Catrina Al, Paget S. Rheumatoid arthritis. Lancet 2009;373:659-72.

3. Rindfleisch JA, Muller D. Diagnosis and management of rheumatoid arthritis. Am Fam Physician 2005; 72:1037-47.

4. Schneider P, Mackay F, Steiner V, et al. BAFF, a novel ligand of the tumor necrosis factor family, stimulates B cell growth. J Exp Med 1999;189:1747-56.

5. Bosello S, Youinou P, Daridon C, et al. Concentrations of BAFF correlate with autoantibody levels, clinical disease activity, and response to treatment in early rheumatoid arthritis. J Rheumatol 2008;35:1256-64.

6. Ohata J, Zvaifler NJ, Nishio M, et al. Fibroblast-like synoviocytes of mesenchymal origin express functional B cell-activating factor of the TNF family in response to proinflammatory cytokines. J Immunol 2005;174:864-70.

7. Melchers F. Actions of BAFF in B cell maturation and its effects on the development of autoimmune disease [abstract]. Ann Rheum Dis 2003;62(Suppl 2): ii25-7.

8. Mackay F, Schneider P. Cracking the BAfF code. Nat Rev Immunol 2009;9:491-502.

9. Moura RA, Weinmann P, Pereira PA, et al. Alterations on peripheral blood B-cell subpopulations in very early arthritis patients. Rheumatology (Oxford) 2010;49:1082-92.

10. Silverman GJ, Carson DA. Roles of B cells in rheumatoid arthritis [abstract]. Arthritis Res Ther 2003;5(Suppl 4):S1-6.

11. Kikly K, Manetta J, Smith H, et al. Characterization of LY2127399, A neutralizing antibody for BAFF [abstract]. Arthritis Rheum 2009;60(Suppl 10):693.

12. Genovese MC, Mociran E, Biagini M, et al. Phase 2 study of safety and efficacy of a novel anti-BAFF monoclonal antibody, in patients with RA treated with methotrexate (MTX). [abstract]. Arthritis Rheum 2009;60(Suppl 10):1923.

13. Arnett FC, Edworthy SM, Bloch DA, et al. The American Rheumatism Association 1987 revised criteria for the classification of rheumatoid arthritis. Arthritis Rheum 1988;31:315-24.

14. Berry DA. Bayesian clinical trials. Nat Rev Drug Discov 2006;5:27-36.

15. Bourdage JS, Cook CA, Farrington DL, et al. An Affinity Capture Elution (ACE) assay for detection of anti-drug antibody to monoclonal antibody therapeutics in the presence of high levels of drug. J Immunol Methods 2007;327:10-17.

16. Edwards JC, Cambridge G. Sustained improvement in rheumatoid arthritis following a protocol designed to deplete B lymphocytes. Rheumatology (Oxford) 2001;40:205-11. 
17. Cohen SB, Emery P, Greenwald MW, et al. Rituximab for rheumatoid arthritis refractory to anti-tumor necrosis factor therapy: Results of a multicenter, randomized, double-blind, placebo-controlled, phase III trial evaluating primary efficacy and safety at twenty-four weeks. Arthritis Rheum 2006;54:2793-806.

18. McKay J, Chwalinska-Sadowska $\mathrm{H}$, Boling $\mathrm{E}$, et al. Belimumab (BmAb), a fully human monoclonal antibody to B-lymphocyte stimulator (BLyS), combined with standard of care therapy reduces the signs and symptoms of rheumatoid arthritis in a

heterogeneous subject population [abstract]. Arthritis Rheum 2005;52(Suppl 9):S710.

19. Genovese MC, Filipowicz-Sosnowska A, Merrill J, et al. Differential responsiveness of belimumab $(\mathrm{BmAb})$ in combination with standard of care therapy in RF+, TNFa inhibitor and MTX partial responder subgroups with moderate-severe rheumatoid arthritis [abstract]. Arthritis Rheum 2005:52(Suppl 9):S1989.

20. Genovese MC, Kinnman N, de La Bourdonnave G, et al. Atacicept in patients with rheumatoid arthritis and an inadequate response to tumor necrosis factor antagonist therapy: results of a phase $\mathrm{II}$, randomized, placebo-controlled, dose-finding trial. Arthritis Rheum 2011;63:1793-803.
21. van Vollenhoven RF, Kinnman $\mathrm{N}$, Vincent $\mathrm{E}$, et al. Atacicept in patients with rheumatoid arthritis and an inadequate response to methotrexate: results of a phase II, randomized, placebo-controlled trial. Arthritis Rheum 2011;63:1782-92.

22. Shaw M, Trapp R, Del Giudice J, et al. The effects of repeated doses of briobacept (Br3-Fc) in patients with rheumatoid arthritis [abstract]. Ann Rheum Dis 2008;67 (Suppl II):87.

23. Tak PP, Thurlings RM, Rossier $\mathrm{C}$, et al. Atacicept in patients with rheumatoid arthritis: results of a multicenter, phase $\mathrm{lb}$, double-blind, placebo-controlled, dose-escalating, single- and repeated-dose study. Arthritis Rheum 2008;58:61-72

24. Lilly discontinues one of three phase 3 rheumatoid arthritis registration studies for tabalumab-FLEX-M study did not meet efficacy expectations in an interim futility analysis; discontinuation not based on safety concerns. Eli Lilly and Company. 13 December 2012.

25. Lilly discontinues phase 3 rheumatoid arthritis program for tabalumab based on efficacy results-decision not based on safety concerns; phase 3 lupus program continues as planned. Eli Lilly and Company. 7 February 2013. 